\title{
Estado da arte das pesquisas sobre ENEM no Brasil
}

\section{State of the art of research on ENEM in Brazil}

DOI: $10.46814 /$ lajdv3n5-018

Recebimento dos originais: 01/05/2021

Aceitação para publicação: 31/06/2021

\section{Dayse Marinho Martins}

Doutora em Políticas Públicas (UFMA), Doutoranda em História (PPGHIS/UFMA)

Professora e Especialista em Educação do Instituto Estadual de Educação, Ciência e Tecnologia do Maranhão (IEMA)

Docente externa permanente PPGPSI/ Mestrado em Psicologia UFMA

Endereço: Reitoria IEMA. R. das Figueiras, 101 - Jardim Sao Francisco, São Luís - MA, 65076-150

E-mail: daysemarinho@yahoo.com.br.

\section{RESUMO}

Levantamento de pesquisas que abordam a percepção das relações entre o ENEM e o currículo do Ensino Médio brasileiro. Realizou-se revisão da literatura especializada sobre o tema, com levantamento de publicações dos últimos 15 anos, buscando identificar artigos em Língua Portuguesa, indexados acerca do tema. A coleta de dados ocorreu em novembro de 2018, com levantamento na base digital de dados da CAPES e da SCIELO com periódicos indexados no período de 2003 a 2018. A partir categorização das pesquisas, apresenta-se a descrição do material selecionado, analisando as peculiaridades dos artigos, tais como o tipo de pesquisa desenvolvida em cada um deles e a discussão empreendida sobre ENEM e Currículo do Ensino Médio no Brasil. A abordagem focada na relação entre ENEM e currículo do Ensino Médio caracteriza oportunidade relevante na perspectiva de compreender a adequação do sistema educacional brasileiro às proposições do exame no âmbito da sociedade globalizada.

Palavras-chave: Ensino Médio. Currículo. ENEM.

\begin{abstract}
Survey of research that addresses the perception of the relationship between ENEM and the Brazilian high school curriculum. A review of the specialized literature on the subject was carried out, with a survey of publications from the last 15 years, seeking to identify articles in Portuguese, indexed on the subject. Data collection took place in November 2018, with a survey in the digital database of CAPES and SCIELO with indexed journals in the period from 2003 to 2018. From the categorization of research, the description of the selected material is presented, analyzing the peculiarities of the articles, such as the type of research developed in each one of them and the discussion carried out on ENEM and High School Curriculum in Brazil. The approach focused on the relationship between ENEM and the high school curriculum characterizes a relevant opportunity from the perspective of understanding the adequacy of the Brazilian educational system to the exam's propositions within the scope of the globalized society.
\end{abstract}

Keywords: High school. Resume. ENEM. 


\section{INTRODUÇÃO}

Na Lei de Diretrizes e Bases (LDB - Lei n ${ }^{\circ}$ 9394, de 20 de dezembro de 1996), em seu art. 2º, a Educação Básica tem como finalidade “[...] o pleno desenvolvimento do educando e seu preparo para o exercício da cidadania”. Nessa configuração, o Ensino Médio, retratado no art. $35^{\circ}$, surge como nível da Educação Básica voltado para “[...] o aprimoramento da pessoa humana, a formação ética e o desenvolvimento da autonomia intelectual e do pensamento crítico.” (BRASIL, 2017, p. 24).

Paralelamente, o sistema de ensino brasileiro tem sua dinâmica norteada pelas políticas de avaliação educacional. A Constituição Federal (CF), de 1988, refere no artigo $206^{\circ}$ “[...] a garantia de padrão de qualidade" no ensino oferecido no sistema público (BRASIL, 2013). Desse modo, corrobora a necessidade de medidas avaliativas.

Segundo SILVA; DIÓGENES; COSTA (2021, p. 2062):

O Estado difunde o argumento de que se faz necessário a criação de políticas educacionais do controle dos resultados, nisto a implantação de avaliações em larga escala é uma das medidas adotadas para a mensuração dos resultados educacionais.

Nesse sentido, o Ministério da Educação (MEC) instituiu, em 1998, o Exame Nacional do Ensino Médio (ENEM), visando à comparação do desempenho dos estudantes ao final do Ensino Médio (BRASIL, 1998). Em 2009, o exame foi modificado a fim de que universidades passassem a considerá-lo na seleção para o ingresso em cursos superiores (BRASIL, 2009). Com as alterações promovidas pelo MEC, em 2009, o Novo ENEM constituiu-se em ENEM-Vestibular. Nas novas funções atribuídas, “[...] deixou de lado a avaliação da Educação Básica, ao ser inteiramente possuído dos requerimentos acadêmicos do vestibular." (CARNEIRO, 2015, p. 422). Assim, teve seus princípios restritos à seleção de alunos para o Ensino Superior e reforçou a perspectiva academicista de Ensino Médio como preparo para o acesso à Universidade.

Torna-se essencial, nessa conjuntura, a realização de pesquisas que abordem a percepção das relações entre o ENEM e o currículo do Ensino Médio brasileiro. Assim, cabe considerar a produção científica brasileira, caracterizando o estado da arte dos estudos brasileiros sobre a referida temática. 


\section{REPERCUSSÕES DO ENEM NA EDUCAÇÃO BRASILEIRA}

Em sua constituição, o Ensino Médio no Brasil se vinculou ao processo de direcionamento da carreira profissional do jovem, educando e fomentando o acesso ao Ensino Superior e à profissionalização. No cenário da contemporaneidade, o mercado informatizado e competitivo reforça o discurso da educação como mecanismo de formação para o mundo do trabalho. Nesse contexto, o Estado brasileiro promove a reinvenção do acesso ao Ensino Superior por meio do ENEM em substituição ao modelo representado pelo vestibular:

O vestibular constitui um mecanismo de passagem entre dois níveis de ensino, mecanismo esse que assumiu a função de um processo de seleção, dadas as condições peculiares do sistema educacional: a expansão da população escolarizada, a tradicional aspiração por formação em nível superior como caminho de ascensão social, concentração de interesse em torno de algumas carreiras e procura preferencial por certos estabelecimentos de ensino. Decorre daí a alta competição pelo ingresso no ensino superior, estabelecida a existência de maior número de candidatos do que de vagas. (RIBEIRO NETTO, 1978, p. 47-48).

O modelo do vestibular, então subsidiado na perspectiva especializada do TaylorismoFordismo, cede espaço ao ENEM como representação das expectativas de flexibilização do Toyotismo. Nota-se, nesse processo, o que Hobsbawn e Ranger (2012) caracterizam como invenção da tradição à medida que o ENEM representa uma construção forjada com base em sistemas de crenças e valores no contexto histórico de uma sociedade. De tal forma, o processo de contextualização do ENEM nas instituições escolares é marcado por rupturas em relação ao currículo, mas também, por muitas permanências quanto à concepção de ensino.

\footnotetext{
Grupos sociais, ambientes e contextos sociais inteiramente novos, ou velhos, mas incrivelmente transformados, exigem novos instrumentos que assegurem ou expressem identidade e coesão social, e que estruturem relações sociais. Ao mesmo tempo, uma sociedade em transformação torna as formas tradicionais mais difíceis ou até impraticáveis. (HOBSBAWN; RANGER, 2012, p. 328).
}

A atribuição de significados ao ENEM abrange um processo relacional por meio de disputas no meio social acerca do que é válido para se estudar em determinado contexto histórico. Conforme Hobsbawn e Ranger (2012), as versões utilizadas na elaboração de uma tradição se reinventam. Desse modo, mudanças acerca da função social da educação suscitaram a reorganização do currículo e das formas de seleção para o Ensino Superior. Promoveram, portanto, a negação das versões vigentes em busca de redefiniç̧ões.

O ENEM representa o ensino voltado para a qualificação com base nas competências valorizadas no mercado. Cabe questionar de que modo a abordagem ampliada do conhecimento pelo ENEM pode ser redimensionada num currículo integrador para uma educação reflexiva. Uma educação emancipadora se fundamenta, portanto, na problematização da realidade pelo educando. Enquanto 
formação, perpassa a compreensão do trabalho como “[...] atividade vital, autônoma e autodeterminada." (ANTUNES; PINTO, 2017, p. 108). Fundamentado nesse pressuposto, o redimensionamento de elementos constituintes do ENEM pode possibilitar o fomento a uma proposta de currículo integrador e problematizante.

A memorização e o acúmulo de conhecimentos outrora valorizados pelo vestibular foram substituídos pela relevância do acesso à informação: pela capacidade e competência do aluno em compreender o que estuda, relacionando com a realidade. (ANTUNES, 2015). A interdisciplinaridade permite compreender a realidade como um todo complexo, e o ser humano enquanto sujeito multidimensional, propondo a superação do ensino fragmentado, pelo diálogo entre disciplinas na ressignificação dos conteúdos e da percepção em relação ao mundo.

O formato problematizante do ENEM constitui elemento para uma formação reflexiva, pois, o discente é levado a pensar no conhecimento numa postura questionadora. Segundo Cassiani, Silva e Pierson (2013, p. 49), “[...] as questões do ENEM evidenciam situações-problema contextualizadas que favorecem a discussão das relações entre ciência, tecnologia e sociedade”. Assim, não condiz estimular o estudante a problematizar somente para realização do exame. Trata-se de instiga-lo à prática por meio da iniciação científica.

Conforme Sousa (1999), Sousa e Alavarse (2009) e Vianna (2003), a matriz de avaliação do ENEM não pode ser tomada como capaz de dar conta do conjunto das atividades curriculares do Ensino Médio. Cabe considerar sua perspectiva significativa de aprendizagem contida na abordagem problematizante dos conteúdos. Entretanto, os sistemas de ensino não devem se restringir a ensinar, concentradamente, os aspectos que constituem as matrizes e os objetos da avaliação, bem como, o formato da prova - com itens de múltipla escolha - configurando um reducionismo curricular e didático.

\section{PESQUISAS SOBRE ENEM NO BRASIL}

No decorrer desta pesquisa, realizou-se revisão da literatura especializada sobre o tema, com levantamento de publicações dos últimos 15 anos, buscando identificar artigos em Língua Portuguesa, indexados acerca do tema. A coleta de dados ocorreu em novembro de 2017, com levantamento na base digital de dados da CAPES e da SCIELO com periódicos indexados no período de 2003 a 2018.

Para a busca na base de dados, foram utilizados os seguintes descritores: ENEM e Currículo do Ensino Médio. Para a seleção dos estudos, todos os descritores deveriam estar contidos no resumo do trabalho. Foram excluídos artigos que não continham os descritores e com fuga ao tema; sendo incluídos, os estudos em Língua Portuguesa, produzidos no Brasil. O critério de seleção considerou artigos que apresentassem no resumo os descritores ENEM e Curriculo do Ensino Médio. A maioria 
dos artigos encontrados contemplavam estudos sobre disciplinas das áreas de exatas no debate acerca da elaboração de questões no estilo do ENEM.

Figura 5 - Seleção de estudos sobre o ENEM e Currículo do Ensino Médio
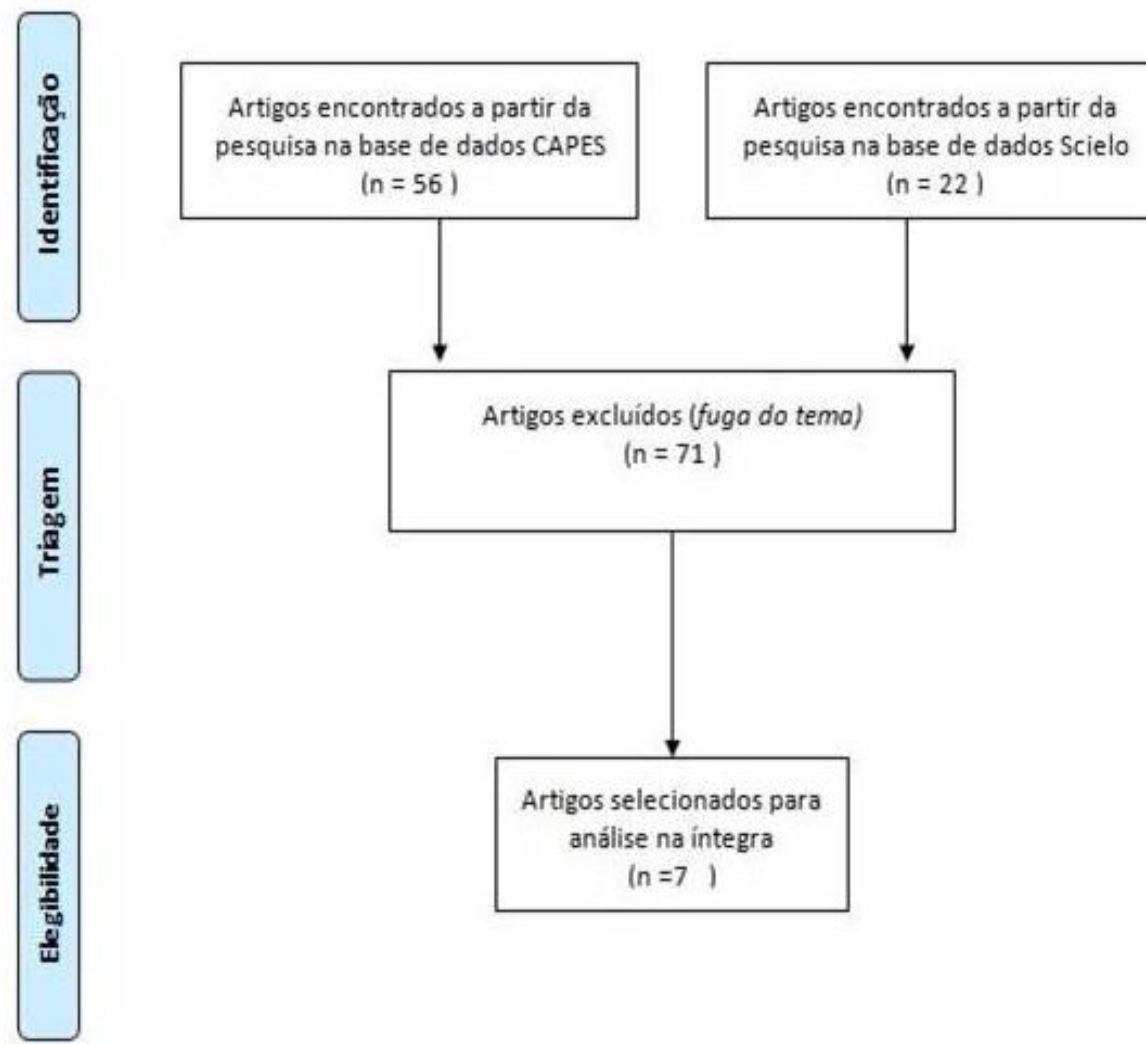

Fonte: Elaborada pela autora, conforme levantamento bibliográfico nos portais CAPES e SCIELO.

Depois de selecionados os estudos para fins de categorização, foi realizada a leitura dos artigos na íntegra. Na organização dos dados, eram descritos o nome da instituição, ano, autor, tipo de estudo, categorias definidas para análise e resumo. Em seguida, procedeu-se à análise de cada estudo.

Com a leitura dos artigos, foram delimitadas as seguintes categorias de investigações de estudos: (1) Teóricos; (2) Aplicados:

Quadro 5 - Categorias de artigos sobre ENEM e Currículo do Ensino Médio

\begin{tabular}{|l|l|}
\hline \multicolumn{1}{|c|}{ Categoria } & \multicolumn{1}{c|}{ Definição } \\
\hline (1) Teóricos & $\begin{array}{l}\text { Levantamentos das formulações conceituais e análises sobre ENEM e } \\
\text { Currículo do Ensino Médio. }\end{array}$ \\
\hline (2) Aplicados & Pesquisas aplicadas com índices sobre ENEM e Currículo do Ensino Médio \\
\hline
\end{tabular}

Fonte: Elaborada pela autora, conforme levantamento bibliográfico nos portais CAPES e SCIELO.

A partir da elaboração da síntese das pesquisas selecionadas, apresenta-se a descrição do material selecionado, analisando as peculiaridades dos artigos, tais como o tipo de pesquisa desenvolvida em cada um deles e a discussão empreendida sobre ENEM e Currículo do Ensino Médio 
Tabela 4 - Quantidade de estudos por categorias de análise

\begin{tabular}{c|c}
\hline \multicolumn{1}{c|}{ Categorias de análise } & Artigos (\%) \\
\hline (1) Teóricos & $05(70 \%)$ \\
\hline (2) Aplicados & $02(30 \%)$ \\
\hline Total & $07(100 \%)$ \\
\hline
\end{tabular}

Fonte: Elaborada pela autora, conforme levantamento bibliográfico nos portais CAPES e SCIELO.

A análise demonstrou que as categorias (1) Teóricos e (2) Aplicados apresentavam diferenças quanto à ocorrência no levantamento. Os artigos qualitativos de perspectiva teórica representaram $70 \%$ do total de estudos selecionados, demonstrando predominância em relação às pesquisas quantitativas de caráter aplicado, cuja ocorrência foi de $30 \%$.

Na categoria (1), Teóricos, o primeiro artigo localizado, A performatividade nas políticas de currículo: o caso do ENEM, foi publicado no periódico Educação em Revista da Universidade Federal de Minas Gerais (UFMG). Lopes e Lopez (2010) discutem nesse estudo os efeitos da globalização no ENEM quanto à produção de uma cultura da performatividade, enfocando a formação para eficiência social do sujeito no sistema capitalista.

No segundo artigo da referida categoria Exame Nacional do Ensino Médio: entre a regulação da qualidade do Ensino Médio e o vestibular, Santos (2011) apresenta o ENEM como medida de avaliação externa. Na publicação, do periódico Educar em Revista da Universidade Federal do Paraná (UFPR), a análise de documentos oficiais apontou o enfraquecimento da função reguladora do ENEM na medida em que as escolas passaram a realizar preparatórios para o exame.

Ainda no grupo de estudos qualitativos, identificou-se o artigo Estudo qualitativo sobre as mudanças que o ENEM provocou nos trabalhos pedagógicos e metodológicos dos professores do ensino médio. Publicado na Revista Espaço do Currículo, da Universidade Federal da Paraíba (UFPB), o estudo de Silva (2012) apresentou os impactos do ENEM nas práticas docentes de avaliação no Pará.

Entre os estudos teóricos, encontra-se o artigo Pensamento e sociedade: contribuiçães ao debate sobre a experiência do Enem, publicado na Revista Educação e Sociedade, do Centro de Estudos Educação e Sociedade (Cedes) pela UNICAMP. Na análise, Ribeiro (2014) problematiza o ENEM no acesso ao Ensino Superior no Brasil na globalização.

Finalizando o grupo de artigos da categoria (1), Teóricos, foi localizado o artigo Vestibular e Enem: um debate contemporâneo, publicado em periódico da Fundação Cesgranrio. Nele, Barros (2014) analisa o ENEM como instrumento de seleção no acesso aos cursos de graduação no 
Brasil, guiado por uma lógica individualista. Nessa conjuntura, sobrepõe-se a responsabilidade individual como determinante para a aprovação dos estudantes, dissimulando os aspectos sociais.

$\mathrm{Na}$ categoria (2), Aplicados, identificou-se a publicação Igualdade de Oportunidades: Analisando o Papel das Circunstâncias no Desempenho do ENEM, da Fundação Getúlio Vargas (FGV). No estudo de cunho quantitativo, Figueiredo, Nogueiray e Santanaz (2014) avaliam como as circunstâncias sociais influenciam o desempenho educacional dos alunos que prestam o ENEM. A abordagem estatística por meio de testagem demonstrou ser o efeito indireto da educação da mãe 2,36 vezes maior do que os efeitos diretos.

O outro estudo, situado na referida categoria, caracterizou o artigo A qualidade do ranking das escolas de ensino médio baseado no ENEM é questionável, pela Revista Estudos Econômicos, da Universidade de São Paulo (USP). No trabalho, Andrade e Soida (2015) questionam a qualidade do ranking das escolas do Ensino Médio baseado no ENEM. Tomando como base a análise das médias, vinculam o tamanho da escola ao desempenho no ENEM e apontam probabilidades para manutenção do ranking.

Os artigos analisados demonstram predominância de pesquisadores de Pós-graduação do campo educacional. Nessa perspectiva, destacam-se os estudos de cunho qualitativo, focados em críticas sobre o ENEM: inicialmente, enquanto mecanismo de avaliação externa, próprio do contexto globalizado. Com, as mudanças no modelo do certame, surgem pesquisas que caracterizam o ENEM como instrumento de seleção para o Ensino Superior. Apesar da mudança na constituição do exame, os estudos mantêm considerações quanto às influências da lógica de mercado, no reforço à performatividade que permeia a ação estudantil.

\section{CONCLUSÃO}

O levantamento evidencia a sobreposição de estudos qualitativos de cunho teórico, especialmente nas pesquisas iniciais. Recentemente, nota-se o despontar de abordagens quantitativas de caráter aplicado, desenvolvidas por estudiosos da Economia. Enfatizando-se os dados obtidos em 20 anos de ENEM, tais iniciativas surgem no sentido de apontar impactos no desempenho estudantil no certame, projeções e possibilidades quanto ao acesso à educação superior.

O Estado da Arte das pesquisas sobre o ENEM no Brasil apresentou baixo índice de estudos quanto à sua relação direta com o currículo no Ensino Médio. A produção científica enfoca práticas preparatórias para o exame em disciplinas de forma isolada, especialmente na área de exatas, evidenciando a dificuldade de percepção do currículo como elemento global permeado pela interdisciplinaridade. 
A abordagem focada na relação entre ENEM e currículo do Ensino Médio caracteriza oportunidade relevante na perspectiva de compreender a adequação do sistema educacional brasileiro às proposições do exame no âmbito da sociedade globalizada. 


\section{REFERÊNCIAS}

ANDRADE, E.; SOIDA, I. A qualidade do ranking das escolas de ensino médio baseado no ENEM é questionável. Estudos Econômicos, São Paulo, v. 45, n. 2, p. 253-286, jun. 2015.

ANTUNES, C. Trabalhando valores e conteúdos no Ensino Médio. Petrópolis, RJ: Vozes, 2015.

ANTUNES, R.; PINTO, G. A. A Fábrica da educação: da especialização taylorista à flexibilização toyotista. São Paulo: Ed. Cortez, 2017.

BARROS, A. da S. X. Vestibular e Enem: um debate contemporâneo. Ensaio: avaliação e políticas públicas em Educação, Rio de Janeiro, v. 22, n. 85, p. 1057-1090, 2014.

BRASIL. Câmara dos Deputados. Constituição da República Federativa do Brasil de 1988. 38. ed. Brasília, DF: Edições Câmara, 2013.

BRASIL. Lei 9.394, de 20 de dezembro de 1996. Estabelece as diretrizes e bases da educação nacional. Diário Oficial da União, Brasília, DF, 2017.

BRASIL. Portaria n ${ }^{\text {438, de }} 28$ de maio de 1998. Institui o Exame Nacional do Ensino Médio. Diário Oficial da União, Brasília, DF, 1998.

BRASIL. Portaria n ${ }^{\circ}$ 462, de 27 de maio de 2009. Altera o Exame Nacional do Ensino Médio. Diário Oficial da União, Brasília, DF, 2009.

CARNEIRO, M. A.. LDB fácil: leitura crítico-compreensiva, artigo a artigo. 23. ed. Petrópolis, RJ: Vozes, 2015.

CASSIANI, S.; SILVA, H. C.; PIERSON, A. (orgs.). Olhares para o ENEM na educação científica e tecnológica. Araraquara, SP: Junqueira \& Marin, 2013.

FIGUEIREDO, E.; NOGUEIRAY, L.; SANTANAZ, F. L. Igualdade de oportunidades: analisando o papel das circunstâncias no desempenho do ENEM. Revista Brasileira de Economia, Rio de Janeiro, v. 68, n. 3, p. 373-392, 2014.

HOBSBAWN, E.; RANGER, T. (Orgs.) A invenção das tradições. Rio de Janeiro: Nova Fronteira, 2012.

LOPES, A. C.; LOPEZ, S. B. A performatividade nas políticas de currículo: o caso do ENEM. Educ. rev., Belo Horizonte, v. 26, n. 1, abr. 2010.

RIBEIRO NETTO, A. R. O vestibular no sistema educacional brasileiro. Cadernos de Pesquisa, São Paulo, n. 24, p. 47-51, 1978.

RIBEIRO, C. R. Pensamento e sociedade: contribuições ao debate sobre a experiência do Enem. Educação e Sociedade, Campinas, SP, v. 35, n. 127, p. 443-460, 2014.

SANTOS, J. M. C. T. Exame Nacional do Ensino Médio: entre a regulação da qualidade do Ensino Médio e o vestibular. Educação em Revista, Curitiba, n. 40, p. 195-205, jun. 2011. 
SILVA, C. S. da. Estudo qualitativo sobre as mudanças que o ENEM provocou nos trabalhos pedagógicos e metodológicos dos professores do ensino médio. Revista Espaço do Currículo, João Pessoa, v.4, n, 2 p.186-196, mar. 2012.

SILVA, Simone da Costa; DIÓGENES, Elione Maria Nogueira; COSTA, Maria Cledilma Ferreira da Silva. A gestão pedagógica face "ao termômetro" da qualidade educacional: o IDEB como modelador de práticas educacionais. Latin American Journal of Development, Curitiba, v. 3, n. 4, jul./ago. 2021.

SOUSA, S. M. Z. L. A que veio o ENEM? Revista de Educação AEC, Brasília, DF, ano 28, n. 113, out./dez. 1999.

SOUSA, S. M. Z. L.; ALAVARSE, O. M. O "novo Enem" democratiza o acesso ao ensino superior e induz melhorias no ensino médio? Não: quem se beneficia dessas alterações? Folha de São Paulo, São Paulo, 23 maio 2009. 